\title{
Mobile Phones and Elderly People: a noisy communication
}

\author{
Stamato, Cláudia ${ }^{1}$ and Moraes, Anamaria de ${ }^{2}$. \\ a Laboratório de Ergonomia e Usabilidade de Interfaces em Sistemas Humano-Tecnologia - Design Department, \\ PUC-Rio/ Brazil. 35, Ministro Armando de Alencar, apt. 1002 - Lagoa, Rio de Janeiro, Brazil. CEP 22471-080 \\ ${ }^{\mathrm{b}}$ LEUI - Laboratório de Ergonomia e Usabilidade de Interfaces em Sistemas Humano-Tecnologia - Design \\ Department, PUC-Rio/ Brazil. 225, Marquês de São Vicente, sala 715F, LEUI - Gávea, Rio de Janeiro, Brazil. \\ CEP 22453-900Pontifícia Universidade Católica - PUC-Rio, Rua Marquês de São Vicente, 225, Gávea-Rio de \\ Janeiro, RJ, Brazil.moraergo@puc-rio.br
}

\begin{abstract}
Knowing the users is capital for building user-friendly digital interfaces. One way to think about the users is considering their familiarity with this technology. This article presents the results of twelve interviews with elderly people residing in the so-called South Zone of Rio de Janeiro (Brazil) who have used mobile phones over at least one year. It is part of the Doctor's Thesis "Mobile phones for elderly people — usability for social integration" ("Celulares para idosos — usabilidade a serviço da integração social"), which is targeted at ascertaining if the current mobile phones are user-friendly for elderly people. Through the technique of Guided Interviews, we found usage time, criteria for choice of phones, reasons for changes, preferences, and manners of use. Preliminarily, we have noticed differences in the behavior of the participating users and performed a qualitative analysis according to groups of age and gender.
\end{abstract}

Keywords: Elderly users, mobile phones, usage, features and preferenes

\section{Introduction}

Communication technology is subject to swift development. Information technology tools such as text editors, web browsers, e-mail and search forms are constantly added to communication devices [10]. The Digital Convergence has been associating computing and information technologies. "No process has had greater impact on the modern world than the digitization of communications and electronics at large, leading to the digital convergence, i.e., the fusion of telecommunications services and products, information technology, multimedia and entertainment in general." [5]. The same author adds "Wireless communication facilitates mobility, freedom, and flexibility, advantages which underlie the phenomenal success of mobile phones in the world."
Wireless connections, Bluetooth, Wi-Fi and Wi-Max networks interconnect everything in a rather smooth way, facilitating the portability - reception of several types of equipment, such as PDAs, laptops and mobile phones with enhanced mobility - reception of software in mobile devices, such as mobile phones, or in moving vehicles, such as trains, buses or cars [5]. The old landline was replaced by the current mobile handset, an individual device which allows communication from most of the places offering connectivity. [5].

The ever-increasing complexity gives rise to the phenomenon of "Information Technology barrier," especially among the elderly. This takes place where users are flustered trying to accomplish a task, but failing, and consequently losing self-esteem due to the said failure [12].

1 Cláudia Stamato. E-mail: stamatoclaudia@gmail.com

2 Anamaria de Moraes. E-mail: moraergo@puc-rio.br 
Concurrently with this phenomenon, we observed another phenomenon, the large-scale acceptance of mobile phones in Brazil. According to Anatel Brazilian Telecommunications Agency, there were 2.9 million new subscriptions in October 2010, which stands as a $1.55 \%$-growth compared to September and establishing the teledensity of 100.44 accesses per 100 inhabitants. At that time, Anatel's President, Mr. Ronaldo Sadenberg, announced that the mobile telephony had surpassed the mark of one cell for each inhabitant [2].

Also according to ANATEL data, by the end of $\mathrm{Au}-$ gust 2011, Brazil had 224 million mobile phones. In October of the same year, the agency released the States which already had more than one mobile phone per inhabitant: The Federal District, which has reached the mark of two mobile phones per capita, São Paulo, with 1.37 mobile phones/inhabitant, Mato Grosso do Sul, with 1.35 mobile phones/inhabitant, and Rio de Janeiro, with 1.29 mobile phones/inhabitant. According to Anatel, 23 States already have more than one mobile phone per inhabitant. The exceptions are the States of Alagoas, Maranhão, Piauí and Pará [4]. Currently, in November 2011 , the national average is 1.18 mobile phones per inhabitant. As the State of Rio de Janeiro is present in this list, we may assert that most of its inhabitants have a mobile phone. In the city of Rio de Janeiro, the neighborhood of Copacabana is recognized by the UN - United Nation - as the location with the greatest number of elderly people compared to the total population. Thus, we may assume that most of its elderly inhabitants also have mobile phones for their communication.

\section{Brazilian Population Aging}

The aging of the world's population is irreversible, and Brazil is no different. In 2005, there were 18.2 million elderly people in Brazil. [7]. In 2025, Brazil will rank six among the countries with more elderly people. Projections point out that there will be 33.4 million elderly people then [13]. The change in Brazilian population status has been happening over 50 years, in a pace which makes it difficult for efficient public policies to be timely implemented. In Europe and the U.S., the same process has been occurring over 150 years. This difference is evident in the treatment of the elderly people, whether by the government or personal approach. The Government seems to be unprepared and slow, and this makes unfeasible the development of awareness-raising programs which value the experience and knowledge of the elderly citizens.

Public unawareness plus government unpreparedness and the swift technology development wind up gradually impairing elderly people engagement with the youngsters, who were born in the digital age.

In the dialog between men and the machine, the optimization of tasks in both sides is evidenced, improving the capabilities of both sides.

\section{The Importance of Communication}

The human need for communication is fundamental. When it comes to the elderly people, it is even more important. This population segment undergoes dramatic losses on all respects of life, leading to their social exclusion [3]. In addition to their physical and cognitive losses, they also have a smaller social group, as their relatives and coevals tend to die of old age. It is then necessary to reconstruct the relationship circle for their own physical and emotional safety. "The social stimulation is based on the communication, affective sharing, interpersonal relationship and sense of belonging - the feeling of being respected, valued and accepted in their social groups [6]. For the communication through mobile phones to be satisfactorily made between individuals, the full understanding of the mobile devices is necessary, so as to get all the benefits from such devices, as they would do with their landlines.

\section{Human-Computer Interaction - HCI}

Within the realm of HCI - Human-Computer Interaction - and Cognitive Ergonomics, the understanding of the system operation, its communicability and user actions resulting from this understanding are the objects of this study. The fact is that, for the full operation of the human $\mathrm{X}$ task $\mathrm{X}$ machine system, understanding the users, the way they perform their tasks, as well as preferences, strengths and weaknesses is necessary.

"Interaction design means creating experiences which enhance and understand the way people work, communicate and interact" [9]. The purpose of the HCI studies is to develop and enhance computer systems in which users may perform their tasks safely, 
efficiently and satisfactorily, taking advantage of their Usability.

On the one hand, the human component has characteristics which favor creativity while performing the tasks, in addition to the focus on relevant issues and decision-making. In its turn, the computational side has features which assist human reasoning by storing data, performing calculations, graphical representations and analyses in a swifter way [8].

Nielsen proved that from 25 to 60 years old, the necessary to complete tasks on sites increases $0.8 \%$ per year of age. [9] The underlying issue is whether this increase is due to the swift technology developments or due to losses brought by the aging. It is important to know how the interface is responsible for the increased time for performing the tasks against the delay time related to the users' inexperience with this type of task or any other variable [11].

Thus, this work is intended to make first contact with the group studied. Based on the data collected with the application of twelve Guided interviews, we qualitatively analyzed the relationship elderly people $\mathrm{x}$ mobile phone. These results and conclusions are part of the data survey for the Doctor's Thesis "Mobile phones for elderly people - usability for social integration." The thesis aims at finding out how to adjust the interface of digital communication via mobile phones to the current population of elderly people in the city of Rio de Janeiro. Its operational objective is to develop some usability guidelines which enhance the use of mobile communication devices for this specific population.

\section{Guided Interview}

An interview is a face-to-face conversation performed methodologically, which allows the interviewer to obtain information from the interviewee verbally, on a subject or issue. This information is acquired from the formulation of questions by the interviewer, in order to obtain data of interest to the research.

We used the Guided Interview in this article. Its application uses a small number of open-end questions. These questions serve as a script of subjects to be explored, which the interviewer brings to the interviewee, who speaks freely as the subjects indicated are referred to.
The Guided interview follows a certain structure, which is related to the ratio of points of interest that the interviewer will explore over the application of the technique. There must be an order and relationship between the points which follow one another. This type of interview is recommended for the cases where the interviewees show some resistance to more closed questions, or to the subject investigated, or due to their cultural condition. The freer expression favors the natural and spontaneous onset of data searched.

The profile of interviewees has the following characteristics: people of both genders from 60 years old living in the city of Rio de Janeiro who use mobile phones over a year and who have high school diplomas at least. There were two men and two women in each age group. The first age group includes participants from 60 to 69 years old and the second group includes participants from 70 to 79 years old, and the last one, from 80 to 89 years old.

The Structure Interviews were divided into four main areas: Profile, Usage, Motivation and Social Relations.

\section{Results of Guided Interviews}

\subsection{Brands, Time of Usage and Change of mobile} phones

The answers relating to the mobile phone brands which were currently used were diverse, but Nokia phones were the most frequent. This finding also occurred when interviewees referred to their former mobile phones. All of them commented about the Nokia (current or previous) mobile phones, pointing to their satisfactory use.

\begin{tabular}{|c|c|c|c|c|c|}
\hline $\begin{array}{l}\text { Brand. } \\
\text { Mobile phones current- } \\
\text { ly used }\end{array}$ & $\begin{array}{l}₫ \\
⿱ \\
0 \\
Z\end{array}$ & $\begin{array}{l}\frac{\pi}{0} \\
\frac{0}{0} \\
\stackrel{0}{0}\end{array}$ & 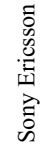 & $\underset{ּ}{\circlearrowleft}$ & $\begin{array}{c}\text { Total } \\
04 \\
\text { Brands }\end{array}$ \\
\hline Number of Participants & 7 & 3 & & 1 & 12 \\
\hline
\end{tabular}

Among the four participants in the first group (60 to 69 years) two uses a smartphone mobile phone, and the others, including other age groups, used simpler mobile phones. Some had Internet access, as 
a secondary function and having slower connectivity, though. The two participants who owned smartphones are male. One of them is retired (although still active) and especially interested in new technologies; and the other still holds a position in the labor market. Among the four participants in the range from 70 to 79 years old, three used Nokia mobile phones and only one uses a Motorola mobile phone, and so does the third group. The male participant of the second group, active in the market and owner of a Motorola mobile phone, has purchased it about three years ago and admitted to be greatly interested in purchasing a Smartphone.

\begin{tabular}{|c|c|c|c|c|c|}
\hline $\begin{array}{l}\text { Partici- } \\
\text { pants from } 60 \\
\text { to } \mathbf{6 9} \text { years } \\
\text { old }\end{array}$ & A & B & $\mathrm{C}$ & D & $\begin{array}{l}\text { Average } \\
\text { Time } \\
\text { with the } \\
\text { current } \\
\text { mobile } \\
\text { phone }\end{array}$ \\
\hline Gender & $\bar{M}$ & $\mathrm{M}$ & $\mathrm{F}$ & $\mathrm{F}$ & \multirow{2}{*}{1.56 years } \\
\hline $\begin{array}{l}\text { Time with the } \\
\text { current mo- } \\
\text { bile phone }\end{array}$ & $\begin{array}{l}1 \\
\text { week }\end{array}$ & $\begin{array}{c}3 \\
\text { months }\end{array}$ & $\begin{array}{c}5 \\
\text { years }\end{array}$ & $\begin{array}{r}1 \\
\text { year }\end{array}$ & \\
\hline $\begin{array}{l}\text { Participants } \\
\text { from } 70 \text { to } 79 \\
\text { years old }\end{array}$ & $\bar{E}$ & F & G & $\mathrm{H}$ & \multirow{3}{*}{ 3.87 years } \\
\hline Gender & $\mathrm{M}$ & $\mathrm{M}$ & $\mathrm{F}$ & $\mathrm{F}$ & \\
\hline $\begin{array}{l}\text { Time with the } \\
\text { current mo- } \\
\text { bile phone }\end{array}$ & $\begin{array}{l}.5 \\
.5 \\
\text { years }\end{array}$ & $\begin{array}{c}3 \\
\text { years }\end{array}$ & $\begin{array}{c}3 \\
\text { years }\end{array}$ & $\begin{array}{r}5 \\
\text { years }\end{array}$ & \\
\hline $\begin{array}{l}\text { Participants } \\
\text { from } 80 \text { to } 89 \\
\text { years old }\end{array}$ & I & $\mathrm{J}$ & $\mathrm{K}$ & $\mathrm{L}$ & \multirow[t]{3}{*}{ 3.37 years } \\
\hline Gender & $\mathrm{M}$ & $\mathrm{M}$ & $\mathrm{F}$ & $\mathrm{F}$ & \\
\hline $\begin{array}{l}\text { Time with the } \\
\text { current mo- } \\
\text { bile phone }\end{array}$ & $\begin{array}{l}2.5 \\
\text { years }\end{array}$ & $\begin{array}{r}1 \\
\text { year }\end{array}$ & $\begin{array}{c}5 \\
\text { years }\end{array}$ & $\begin{array}{r}5 \\
\text { years }\end{array}$ & \\
\hline
\end{tabular}

Table 2: Individual and average usage time of the current mobile phone per age group

The average usage time of the current mobile phone among the participants of the second group increases significantly compared to the first one. The longer use of a single device may indicate a weaker interest in technology upgrades. We may argue that the cause may be attributed to the lack of necessity for new features and/or applications for its communication and the difficulty entailed by more complex devices.

The average usage time difference between participants of the second and third groups is small. We expected a larger difference, with more usage time in the last group. Relating to the total time of use of mobile phones (since the purchase of their first mobile phone), participants of the first age group presented an average nine years. The group of participants from 80 to 89 years old was surprising, as the average usage time was nine years and a half, higher than the group aging from 60 to 70 years old (seven years).

According to the accounts, some participants of all age groups had their first mobile phones soon as the service was firstly provided in Brazil. Some of them were encouraged by the newness, and others intended to have professional benefits of their usage, but most of them wished to communicate easier with their relatives, especially those living in other cities.

\subsection{Criteria and Reasons for Purchasing and} Changing mobile phones

Over the time of usage of mobile phones, participants in the group of 80 years old made an average three changes, the first one happening due to the size and weight of the devices. The group with 60 years old made at least two device changes, while those in the group of 70-year old participants had changed their devices only once on average. Typically, most participants affirmed that they refrain from changing their phones to the most possible, and only change it if the former one breaks, is stolen or are too old. Only one participant (in the first age group) affirmed differently that he performs changes owing to technology advancements. $\mathrm{He}$ is interested in purchasing a $4 \mathrm{G}$ mobile phone.

In the pursuit of Internet access and also due to the features that a smartphone may mean for one participant in each one of the groups (all of them owners of simple mobile phones), the said participant affirmed to be interested in purchasing one. The status of the most modern mobile phones, allowing higher communication capacity has called attention of old age groups.

Paradoxically to the technological needs of these three groups, the simplicity of the phone, as well as of its navigability, and the price and/or freedom due to the bonus points are criteria considered in the change of a mobile phone. They argued that complexity is a characteristic which makes their usage difficult.

Participants in the second and third groups pointed to one more criterion to purchase or change their phones: the newness or the promise of newness.

However, participants in all age groups barely choose their mobile phones, as they get them as gifts from their children. Only two participants in the 60aged group pointed out more selection criteria. One of them pointed to the existence and ease of use of spreadsheets, which improved customer service on an 
immediate basis, and the other said that the brand (a brand which he trusted of had previous good experience), its light weight, the battery life, the Internet access, minimum sophistication and the fact it is not a touch screen model were important criteria.

The four participants in the 60- aged group and most of the participants in the other groups admitted they had a phone primarily for business purposes. In second place, for communication with relatives, followed by friendly relations.

\subsection{Portability X Security}

For these reasons, all three reported to carry their mobile phones daily. Only one participant (60-aged group) admitted to use it sparely, leaving it at home in leisure or introspection moments (as in water aerobics classes, at the movies or in waterfront walks) when such participant wants not to be interrupted.

Three male participants (one for each group) and one female participant of second group admitted to return home when he/she forgets the device, especially if there are important activities and/or contacts to be made. Although they carry it daily, most (of the three groups) reported "not to be a disaster" if they forget it at home. Nevertheless, they affirm to miss it and prefer to have them on due to the commodity they had already get use to having.

It is a result which is consistent with the unanimous statement among the 60-aged group participants, and three out of four participants in the 70 -aged group, which directly relate the carrying of a mobile phone with the sense of safety. This sense was referred to as a specific reference for emergency cases such as a flat tire, a broken car, an accident, the safety assurance by relatives and the needs of other people, such as children and grandchildren.

The participants of the last group, in their turn, had an inversely proportional opinion. Three of the four participants do not relate the mobile phone with safety, and only one male participant still present in the labor market agrees with most of the other groups. The feeling of safety for carrying a mobile phone is directly related to the anticipation of solving of a problem and, therefore, reduced of the time of exposure to a risk.

It should be noted that the relationship established between the forgetfulness of a mobile phone at home (often only noticed when returning) or forgetfulness of the device turned off with the negative sense of safety which a turned-on cell may provide. This occurs principally to the third age group.

\subsection{Functions Used X Not Used X Computer Usage Time X Social Networks}

Table 3 shows the functions used in mobile phones by participants of all age groups. It is clear the steady decline of usage acquaintance as the age increases. The main functions are used to send and receive phone calls, followed by the identification and reading of a received text message. However, sending a text message is reduced to the second age group and disappears in the third one.

\begin{tabular}{|l|l|l|l|l|l|l|l|l|l|l|l|l|}
\hline Functions used & & & & & & & & & & & & \\
\hline & & & & & & & & & \\
\hline \\
\hline
\end{tabular}

Table 3 Demonstration of the functions used by the participants on their mobile phones

The most frequent complaint was related to the small size of the letters (different from the number sizes) and the keyboard structure with three letters and one number per key. Details on how to use capital letters, punctuation marks, spaces and corrections 
are also reasons for doubt and even for giving up using the function. Only the participants of the first group and one of second group referred to the commercial importance of the mobile device.

Most of thse send and read text messages. This single interviewee of the second group has also asserted to prefer sending a text message than calling, for business purposes. He said it helps achieve his goal more swiftly.

Although the phonebook has appeared as a function with which most participants were conversant, is important to note that of participant in the second group and three in the third group were unaware of the procedures for including contacts. They used only as names for the reference for performing calls. The said three participants also asserted that their children were responsible for including information in general on their mobile phones. The definition of which functions must be included in Tables 3 and 4 was exclusively made based on the free account of the participants. Only the information which were referred to in some way was included, be it the functions used, or the functions known but not used for lack of skills.

Participants aged between 60 and 69 years referred to use more (five) functions, as opposed to other groups, whose members were unaware of them. They included functions such as: games, spreadsheets, voice recording and notes. Those in the group from 80 to 89 years old referred to four functions, namely: alarm/alarm clock, bluetooth, read text messages, block keyboard and sound volume/ringtones. Those ranging from 70 to 79 years old reported the use of phonebooks and GPS, which differed from the others. Common answers to the three groups were: send text messages, movie recording, Internet and listen to music. Initially, one could refer to the convenience of text messaging to the continuity in the labor market. Nonetheless, three of the four participants in the second group are wage-earners and two of them prefer not to resort to this feature. Among participants of the 70-to-60-aged group, there is a difference in the purpose of using the phone. Those in the first group and one male participant of the second group make $80 \%$ of their use for business purposes. This is different from those of the second and third groups. Furthermore, we noticed a decrease in the amount and quality of usage of the features due to their phones. The usage of a mobile device reported by the participants in the 80 -aged group is still lower than the usage reported by the 70 -year-old participants. The ones in the last group are limited to verbal communication. Two of them admitted that they only know how to write messages, but that they did not use such function.

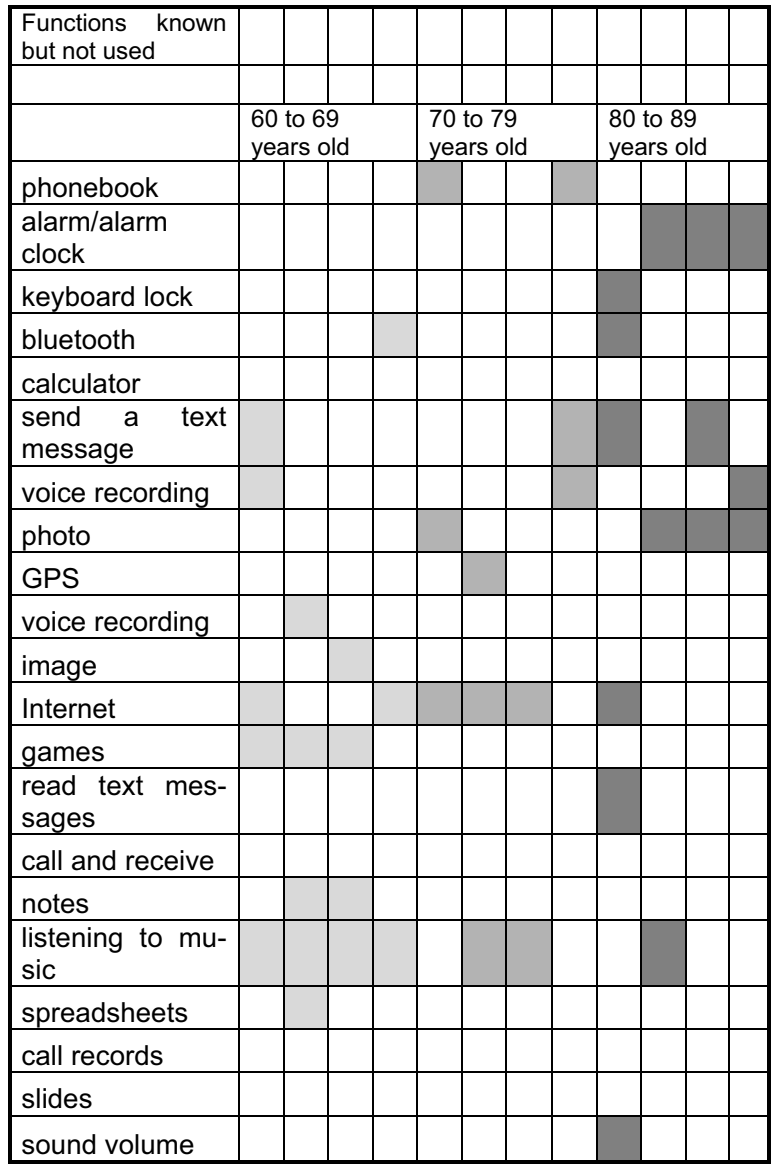

Table 4 - Presentation of the functions known by the participants, but who are unacquainted with the manner of using them.

As for the use of computers, only three participants in the group of 80 to 89 years old admitted that they have never used it (the two women and one man). The second man has used computer for ten years, though. The average of years of computer use was 22 years for participants aged 60 to 69 years old, 14.5 years for participants aged 70 to 79 years old, and 2.5 years for those aged 80 to 89 years old.

This variation is somehow consistent with the list of functions used by each younger age group, which tends to have greater knowledge of procedures and use of mobile phones. The more is the convergence of a given mobile phone, the greater is its complexity, and the closer is the likeness with the computer language.

When asked about the presence on social networks, only two participants in the first group (one man and 
one woman) and two participants in the second group (two women) confirmed its use. In order of frequency, three participate in the Skype, and two in the Facebook. The male participant aged 60 years old, besides being present in the said two networks, is also registered on Twitter; and the female participant in this same group is also present in the MSN, in addition to Skype. The two female participants aged from 60 to 69 years reported that they wanted to register in Linkdln. This result is similar to the finding related to the more professional usage of the mobile phone by participants of the same age. One male participant in the first group, two in the second group and all participants in the third group showed no interest or saw no importance in the use of social networks.

It should be noted that the two male participants in the group of 70 to 79 years old have average 14.5 years of computer use, but that did not seem to call their attention to social networks.

6.5 Mobile phone Usage X Changes in Social and Professional Relations

Participants were asked if there was any change to personal and professional relationships due to the usage of the mobile phone. Ten of the twelve participants reported that there had been no changes in quality or quantity of contacts and personal and professional relationships. It only seemed easier, from any place and at any time. The two women aged 60 to 69 years old said they had noticed changes in professional relationships. They noticed an increase in opportunities from the new swifter manner of communication. All of the participants understood that there was a rapprochement with third parties, due to easy communication. However, the bonds of love, friendly, family or professional relationships have not changed.

The participants of all ages somehow considered that the mobile phone was an invasive device. Several adjectives were used: inconvenient, annoying, long-range (even abroad), at any time. According to the accounts, the user's behavior is the element of discomfort. While all participants from 60 to 69 years old and one man from 70 to 79 years old informed their mobile phone numbers to a wide range of people, such as customers, potential customers, suppliers, bank managers, as well as friends and family. These same participants also refuse to inform it to general trade, such as shops and businesses, so as to avoid invasion of privacy through telemarketing. The three other components of the 70-to-79-aged group (one man and two women) said they had few names on their phonebooks and had the habit of informing their phone number to the stores where they used to shop. The four participants of the 80-to-89-aged groups do not care about this. They have very few names registered in their phonebooks, are hesitant to inform their mobile numbers and receive very few calls. They virtually use it only with their relatives and a limited group of friends. In this group, the two women seem to make more frequent use of phone calls than men.

Half of the participants said to bother with the manner of mobile phone use by others in public places, due to the lack of good sense and education: they speak out and share compulsorily their personal lives. They also pointed out friends and relatives who used to answer their phone calls in the most intimate moments of a conversation in a meeting or during a play. Privacy is believed not to be respected.

6.6 Difficulties in the usage $\mathrm{X}$ Physical Aspects $\mathrm{X}$ Understanding of Icons and Feedback Messages

Firstly, three quarters of the participants said they had no difficulties in using their phones. While answering to other questions, difficulties of legibility and fine movements relating to the keys and letter sizes were the first problems commented; followed by the lack of understanding about the successive levels of information: third, the doubt caused by the representations of icons; and finally the misunderstanding of feedback messages. Few icons were understood by the participants of the second and third groups. The youngest age group understood about $40 \%$ of the icons and terms related to Information Technology. At least three out of the four participants from the 60-to-69-aged group understood the icons of "Phonebook (contact)," "Internet," "Messages,"

"Records (call)," "Settings and Tools," "Media" and "Calendar/Organizer."

However, this learning is not only attained by the relation of form and meaning. It mainly happened to the opposite direction of usability. Firstly, they tried and tested without understanding the meaning, to discover what it was. In a second moment, they understood what that function performed and, finally, they related the image to the function which it performed and this produced a meaning. The joint use of mobile phone and computer favored a swifter learn- 
ing. Even though, when they changed their mobile phones, they saw differences in the interface and were taken back to the first step and, if necessary, referred to the instruction manual, although unwilling to do that.

There is a sharp decrease of understanding among the participants of the age group of 70 to 79 years old. They recognize "Messages," "Contacts," "Media and Camera" and began to understand the "Records." The participants in the group of 80 to 89 years old showed no interest in learning. Three out of four said they had a mobile phone only to talk to people when they are not at home and do not miss the functions which were never available in other forms of communication. They recognize "Messages" and "Contacts."

\section{Conclusion}

Direct contact with elderly mobile phone users fosters a greater understanding of their behavior and universe. What sprang to the eyes as to the use of mobile phones were some major influences:

1) Being in the labor market, despite retirement;

2) Having continuous and uninterrupted experience with computers and other digital media;

3) Dealing with their relationship network continuously, having contact with younger people who are more acquainted with media and meeting with friends, family and professionals.

Reaction towards innovations in all of the three different age groups differs not only by the curiosity raised but by the subsequent attitude of buying, testing and experimenting. The older participants became interested in the mobile phones as soon as they arrived in Brazil, even without really knowing about the benefits. These participants were ten to fifteen years younger than they are today. As for the mobile phones, men were found to be more comfortable in relation to more complex and innovative items such as smartphones than women. On the other hand, women are apparently those who use it more often in order to keep their working and family network well fed.
Although carrying high-tech products means having information in advance, and learning from one phone to another is an upward curve, changes are still moments of tension and irritation until the user adapts to the new device and their interaction becomes less disrupted. Systems with lower levels of information, reduced features (or customization of features enabled), enlarged letter sizes, individual keys for numbers and letters, increased battery life and screen brightness and keyboard on the device, increasing the volume of sound and touch, light weight and overall dimensions as small as possible without compromising the physical interaction, are suggestions for improvements from contact with the twelve participants.

\section{References}

[1] A. C. Gil, Métodos e Técnicas de Pesquisa Social. Editora Atlas, São Paulo, 2007. pp120-121

[2] Brasil já tem mais de um celular por habitante Divulgado em 19/10/10 - Acesso em outubro 2011. Disponível em http://www.ipnews.com.br/telefoniaip/index.php?option=com content\&id=19720\&task=view

[3] C. Stamato, Modelo de banheiro residencial para idosos - uma abordagem ergonômica. Dissertação de Mestrado. Depto. Design - PUC-Rio, 2007

[4] DF já tem dois celulares por habitante Divulgado em 21/11/11 Acesso em novembro 2011. Disponível em http://www.ipnews.com.br/telefoniaip/index.php?option=com content\&view $=$ article\&id $=22745$ :df-ja-tem-dois-celularespor-habitante \&catid $=38$ : wireless \&Itemid $=580$

[5] E. Siqueira, Para compreender o mundo digital. Editora Globo, São Paulo, 2008 pp 49/191/192

[6] G. Zimmerman, Velhice e aspectos biopsicossociais. ArtMed, Porto Alegre, 2000

[7] IBGE- Instituto brasileiro de Geografia e Estatística - Pesquisa Nacional de Amostra de domicilio in Síntese de Indicadores Sociais - Uma análise das condições de vida da população brasileira, 2008

[8] Acesso em novembro 2011 Disponível em http://www.ibge.gov.br/home/estatistica/populacao/condicaod evia/indicadoresminimos/sinteseindicsociais2008/indic sociai s2008.pdf

[9] J. Preece, Y. Rogers e H. Sharp, Design de Interação - Além da interação homem-computador. Bookman, Porto Alegre, 2007 pp 28

[10]J. Royo, Fundamentos do Design. Edições Rosari, São Paulo, 2008, pp 11

[11]R. Pak and A. Mclaughlin, Designing Displays for older adults. CRC Press - Taylor \& Francis Group, 2011

[12]W. Cibys, Ergonomia e Usabilidade. Novatec, São Paulo, 2007, pp 14

[13]WHO (World Health Organization). Active Aging: A Policy Framework. Second United Nations World Assembly on Aging. Madrid, 2002 